\title{
Artists and psychoactive substances use
}

\author{
Efthymia Patsika, Minerva-Melpomeni Malliori
}

MSc Treatment of Addictions, Medical School, National and Kapodistrian University of Athens, Athens, Greece

ARTICLE HISTORY: Received 30 May 2020/Revised 14 September 2020/Published Online 17 March 2021

\begin{abstract}
It is a well-established common notion that artists appear to use and abuse psychoactive substances more frequently and heavily than non-artists. The purpose of this study was to investigate if this holds true. The sample consisted of 118 participants, both artists and non-artists. They were asked to complete the ASSIST questionnaire, developed by the World Health Organization, that includes closed questions on substance use along with an additional questionnaire on demographic characteristics. The questionnaires were posted online in a digital platform. The artists scored significantly higher on substance use than the other professionals. Women reported less psychoactive substance use compared to men. The results confirmed the study hypothesis, in line with previous research findings. The number of similar studies in the international literature is limited. Our results are particularly useful but due to significant limitations of this study further investigation is suggested, as well as further examination of the causes of the phenomenon.
\end{abstract}

KEYWORDS: Artists, psychoactive substances, alcohol, substance use, art.

\section{Introduction}

The mistaken social perception that alcohol and substance use stimulates artistic creation has prevailed for thousands of years. ${ }^{1}$ At the same time, the Media propagate that art professionals tend to use or abuse psychoactive substances. ${ }^{2}$ Recognizing a privileged relationship between artists and substance use, the artists' need for expression, creation and imagination is determined. Secondarily, the social attribution of symbolic meanings in substance use by artists is also highlighted. ${ }^{3}$

The present cross-sectional study investigates the rates of psychoactive substance use among artists and non-artists.

\section{Material and Method}

The avalanche approach was used as a sampling method. The sample consisted of a group of artists, who were professionally engaged in at least one of the nine fine arts, and a group of professionals from other disciplines. The participants were 118 , with an average age of 30.7 years ( $\mathrm{SD}=6.9$ years), 57 of whom were artists. More specifically, $11.9 \%$ of artists were professionally engaged in theater, $11 \%$ were architects, $11 \%$ were musicians, $7.6 \%$ were working in the field of visual arts, $4.2 \%$ were cinematographers, $0.8 \%$ engaged in poetry, $0.8 \%$ in photography and $0.8 \%$ in comics (table 1 ).

Assessments were conducted with the ASSIST questionnaire, which provides information on lifelong substance use, use in the last three months, problems with use, dependence, injectable use and risk of harm. ${ }^{4}$ The questionnaire was distributed and completed on an online platform.

Pearson's chi-squared test or Fisher's exact test were used to compare ratios, where necessary. The Student's t-test or the Mann-Whitney U non-parametric test were used to compare quantitative variables between the two groups. Linear regression analysis with stepwise integration/subtraction was used to identify independent variables related to the use scores for various substances. The linear regression analysis was performed using

Corresponding author: Efthymia Patsika, MSc Treatment of Addictions, Medical School, National and Kapodistrian University of Athens, 25 Alexandroupoleos street, GR-115 27 Athens, Greece•e-mail: efthimiapatsika@gmail.com 
Table 1. Demographic characteristics in total sample and comparisons between artists and non-artists.

\begin{tabular}{|c|c|c|c|c|c|c|c|c|}
\hline & & \multirow{2}{*}{\multicolumn{2}{|c|}{$\begin{array}{l}\text { Total Sample } \\
(\mathrm{N}=118)\end{array}$}} & \multicolumn{4}{|c|}{ Are you an artist? } & \multirow[b]{3}{*}{$\mathrm{p}$} \\
\hline & & & & \multicolumn{2}{|c|}{ No $(\mathrm{N}=61,51.7 \%)$} & \multicolumn{2}{|c|}{ Yes $(\mathrm{N}=57,48.3 \%)$} & \\
\hline & & $\mathrm{N}$ & $(\%)$ & $\mathrm{N}$ & (\%) & $\mathrm{N}$ & $(\%)$ & \\
\hline \multirow{2}{*}{ Sex } & Men & 50 & 42.4 & 24 & 39.3 & 26 & 45.6 & \multirow{2}{*}{$0.491 *$} \\
\hline & Women & 68 & 57.6 & 37 & 60.7 & 31 & 54.4 & \\
\hline \multirow[t]{3}{*}{$\begin{array}{l}\text { Age, } \\
\text { mean value (SD) }\end{array}$} & & \multicolumn{2}{|c|}{$30.7(6.9)$} & \multicolumn{2}{|c|}{$32.5(8.0)$} & \multicolumn{2}{|c|}{$28.8(4.8)$} & $0.004 \ddagger$ \\
\hline & Secondary & 7 & 5.9 & 4 & 6.6 & 3 & 5.3 & \multirow{5}{*}{$0.099 * *$} \\
\hline & Vocational institute & 2 & 1.7 & 1 & 1.6 & 1 & 1.8 & \\
\hline \multirow[t]{3}{*}{ Educational level } & $\begin{array}{l}\text { Higher education institutes/ } \\
\text { Technology higher institutions }\end{array}$ & 58 & 49.2 & 23 & 37.7 & 35 & 61.4 & \\
\hline & Master's degree & 43 & 36.4 & 28 & 45.9 & 15 & 26.3 & \\
\hline & Doctorate & 8 & 6.8 & 5 & 8.2 & 3 & 5.3 & \\
\hline
\end{tabular}

*Pearson's chi-square test; ${ }^{* *}$ Fisher's exact test; $\neq$ Student's t-test

logarithmic transformations. Significance level was set at 0.05 . The SPSS 22.0 was used for the analysis.

\section{Results}

Almost all participants (98.3\%) were found to consume alcohol, while the rate for tobacco use was also high $(83.1 \%)$. The median number of substances used amounted to three, i.e., $50 \%$ of the sample had used up to three substances (int. Range: w2-5). Use of cannabis, cocaine, amphetamine-type stimulants and hallucinogens was significantly higher in artists than in non-artists (table 2). Moreover, the number of substances used by artists cumulatively was significantly higher than that used by non-artists. Risk levels relating to psychoactive substances dependence (low, moderate, high) were similar for artists and non-artists.

In the multiple linear regression models, use scores for each substance and the overall score were the dependent variables, and age, sex, educational level and the distinction between artists and non-artists were the independent variables. According to these models, age was the only variable significantly related to alcohol and cannabis use scores. More specifically, the older the participants the less they used alcohol and cannabis.

Also, sex and the distinction between artists and non-artists were found to be related independently to the overall substance use score. Women scored significantly lower, i.e., they used less psychoactive substances compared to men. Finally, artists overall reported significantly higher scores compared to non-artists.

\section{Discussion}

Artists in our sample used cannabis, cocaine, amphetamine-type stimulants and hallucinogens at significantly higher rates compared to non-artists. Furthermore, the number of psychoactive substances used by artists cumulatively was significantly higher than the corresponding number for non-artists. The above findings are consistent with the results of a previous study that examined the use of psychotropic substances and psychopathology in art students and students of other disciplines and found that fine arts students try more types of psychoactive substances and use more cannabis and alcohol, compared to students of other disciplines. ${ }^{2}$ Our findings are also consistent with a previous study that focused on the potential correlation between creativity and psychopathology in a sample of 80 artists and 80 non-artists and found that higher use of psychoactive substances in artists. Furthermore, artists used illicit psychotropic substances in significantly higher levels than non-artists. ${ }^{5}$ In another study professional artists also showed higher rates of alcohol and drug abuse compared to other professionals. ${ }^{6}$

Multiple regression analysis revealed some interesting findings. More specifically, age was found to be significantly associated with alcohol use. The older the participants were the less alcohol they used. Age was also significantly associated with cannabis use. Overall, the use of all reported substances was lower in women than men. Artists used more substances and more types of substances compared to other individuals in the sample.

Our study has significant limitations. Selecting artists in nine fine arts and excluding artists of the applied arts may be obsolete today, as it involves a narrow perception of the artist's identity and their means of expression. Furthermore, it is suggested that an official society or association should recruit the artists to be involved in future studies, as our sample was limited to individuals who identified themselves as artists, following, of course, certain criteria that were set. Furthermore, the 
Table 2. Use scores for each substance and the total score in the sample total and comparisons between artists and non-artists.

\begin{tabular}{|c|c|c|c|c|c|c|c|}
\hline \multirow{3}{*}{ Use rate } & \multirow{3}{*}{$\begin{array}{c}\begin{array}{c}\text { Total Sample } \\
(\mathrm{N}=118)\end{array} \\
\text { Mean value } \\
\text { (SD) }\end{array}$} & \multicolumn{5}{|c|}{ Are you an artist? } & \multirow{3}{*}{$\begin{array}{c}\mathrm{p} \\
\text { Mann- } \\
\text { Whitney } \\
\text { test }\end{array}$} \\
\hline & & \multicolumn{2}{|c|}{ No $(\mathrm{N}=61,51.7 \%)$} & \multicolumn{2}{|c|}{ Yes $(\mathrm{N}=57,48.3 \%)$} & \multirow[b]{2}{*}{$\begin{array}{c}\text { Median } \\
\text { (Int. Width) }\end{array}$} & \\
\hline & & $\begin{array}{c}\text { Median } \\
\text { (Int. Width) }\end{array}$ & $\begin{array}{c}\text { Mean value } \\
\text { (SD) }\end{array}$ & $\begin{array}{c}\text { Median } \\
\text { (Int. Width) }\end{array}$ & $\begin{array}{c}\text { Mean value } \\
\text { (SD) }\end{array}$ & & \\
\hline Tobacco products & $13.83(8.05)$ & $15(7-20)$ & $13.73(8.06)$ & $15(9-20)$ & $13.92(8.12)$ & $15(7-18)$ & 0.909 \\
\hline Alcohol & $10.91(7.69)$ & $9(5.5-14.5)$ & $9.81(7.31)$ & $7(4-14)$ & $12.04(7.98)$ & $9(7-15)$ & 0.057 \\
\hline Cannabis & $7.24(7.55)$ & $6(2-11)$ & $5.38(5.95)$ & $3(0-8)$ & $8.68(8.37)$ & $7(2.5-12.5)$ & 0.071 \\
\hline Cocaine & $3.55(4.53)$ & $2(0-6)$ & $2.64(2.76)$ & $2(0-5)$ & $4.04(5.23)$ & $2(0-8)$ & 0.847 \\
\hline $\begin{array}{l}\text { Amphetamine-type } \\
\text { stimulants }\end{array}$ & $2.76(4.06)$ & $2(0-3)$ & $1.73(1.95)$ & $2(0-3)$ & $3.19(4.65)$ & $2(0-5)$ & 0.699 \\
\hline Inhaled substances & $1(1.63)$ & $0(0-2)$ & $1.25(2.12)$ & $0(0-2)$ & $0.75(1.04)$ & $0(0-2)$ & 0.854 \\
\hline $\begin{array}{l}\text { Sedative or sleeping } \\
\text { pills }\end{array}$ & $5.6(8.41)$ & $3(0-6)$ & $3.63(4.21)$ & $2.5(0-6)$ & $7.86(11.54)$ & $3(0-22)$ & 0.857 \\
\hline Hallucinogens & $1.32(1.74)$ & $0(0-3)$ & $1.38(2.2)$ & $0(0-2.5)$ & $1.3(1.59)$ & $0(0-3)$ & 0.842 \\
\hline Opioids & $1.75(2.14)$ & $1(0-3)$ & $2.2(2.49)$ & $2(0-3)$ & $1.43(1.99)$ & $0(0-3)$ & 0.542 \\
\hline Other & $5.5(7.78)$ & $5.5(0-11)$ & - & - & $5.5(7.78)$ & $5.5(0-11)$ & - \\
\hline Overall use rate & $41.74(27)$ & 37 (19-59) & $35.1(22.72)$ & $32(17-52)$ & $48.84(29.5)$ & $42(29-73)$ & 0.011 \\
\hline
\end{tabular}

sample size of the present study is relatively small for generalization of our findings to the population under consideration. The choice of a purely quantitative method also poses some limitations. A more detailed investigation would be useful, including, for example, possible causes of the phenomenon, the combination of the quantitative and the qualitative method, comparisons with rates reported by official Greek institutions, and associations with other demographic characteristics.

\section{References}

1. Holm-Hadula RM, Bertolino A. Creativity, alcohol and drug abuse: The pop icon Jim Morrison. Psychopathology 2014, 47:167-173, doi: $10.1159 / 000354617$

2. Iszáj F, Kapitány-Fövény M, Farkas J, Kökönyei G, Urbán G, Griffiths $\mathrm{MD}$ et al. Substance use and psychological disorders among art and non-art university students: An empirical self-report survey. Int J Ment Health Addict 2017, 16:125-135, doi: 10.1007/s11469-017-9812-5

3. Poulopoulos Ch. Art, Drugs and Rehabilitation. Addictions 2013, 21:1116 (In Greek)
Finally, the research did not deal with the essence of the specific artistic practices at this stage; it is worth noting, however, that practices may differ according to the category of artistic expression. Instead, we focused on approaching the demographics of the artists. This question could be part of future research. We should investigate the differences between art types as well as the degree substance use is involved in specific practices followed by individual artistic expressions.

4. Henry-Edwards S, Humeniuk R, Ali R, Poznyak V, Monteiro M. The alcohol, smoking and substance involvement screening test (ASSIST): Guidelines for use in primary care (Draft version 1.1 for field testing). World Health Organization, Geneva, 2003

5. Preti A, Vellante M. Creativity and psychopathology. Higher rates of psychosis proneness and non-right handedness among creative artists compared to same age and gender peers. J Nerv Ment Dis 2007, 195:837-845, doi: 10.1097/NMD.0b013e3181568180

6. Ludwig AM. Creative achievement and psychopathology: comparison among professions. Am J Psychother 1992, 46:330-356, doi: 10.1176/ appi.psychotherapy.1992.46.3.330 


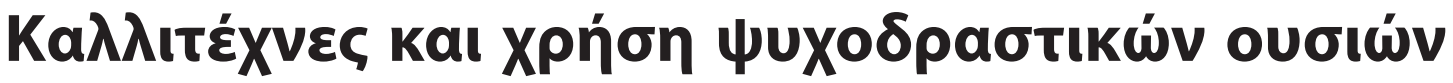

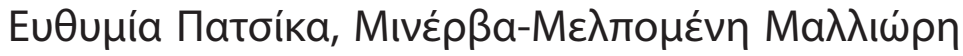

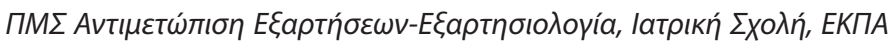

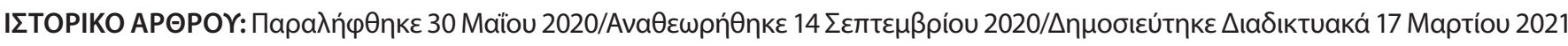

\begin{abstract}
ПЕРІАНЧН

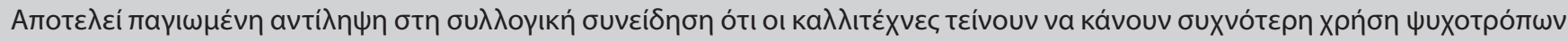

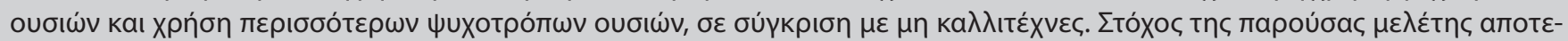

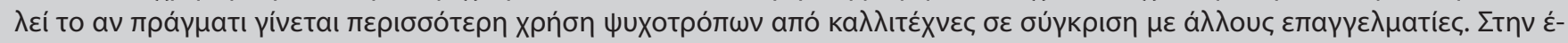

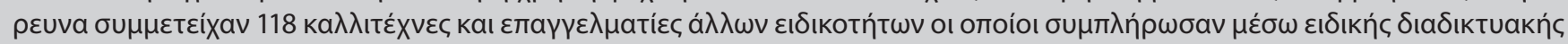

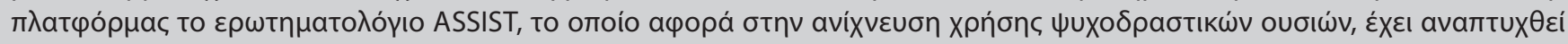

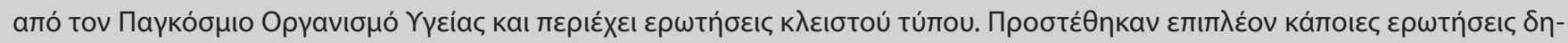

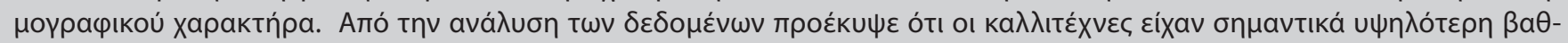

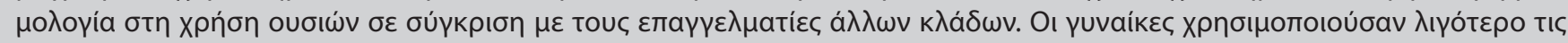

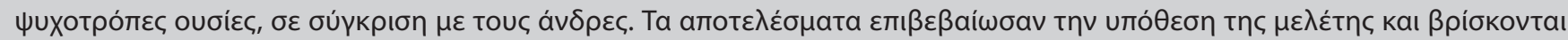

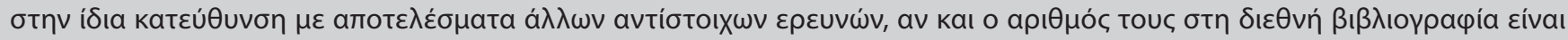

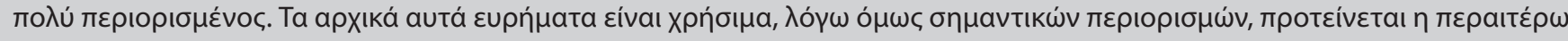

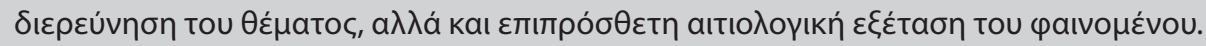

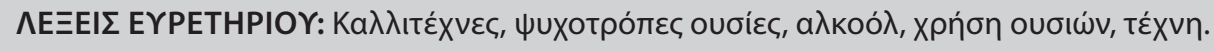

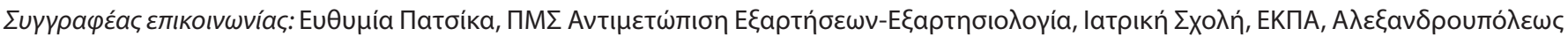
25, 11527 AӨńva, $\Delta$ ıยúӨuvon e-mail: efthimiapatsika@gmail.com 